\section{Absolute Value of the X-Unit}

$I_{N}$ order to determine the ratio between the $\mathrm{X}$-unit and the absolute unit of length, I have registered certain $\mathrm{X}$-ray lines in high orders with a concave glass grating $(R=5 \mathrm{~m}$.) and determined their wavelengths by comparing them with known spark lines in the first order, registered on the same plate ${ }^{1}$. The X-ray line which turned out to be most suitable for such relative measurements was the aluminium $K \alpha_{1} \alpha_{2}$ line, which has been determined very accurately by Larsson ${ }^{2}$ with a crystal grating. From nine different plates I have found the values given in the accom. panying table. The value found by Larsson is Al $K \alpha_{1} \alpha_{2}=8322 \cdot 48$ X.U., or, corrected for the refraction in the crystal, $8321 \cdot 35$ X.U. The difference $\Delta \lambda$ between the measured values and the crystal determination is given in the second column. For every value found for the $\mathrm{Al} K \alpha_{1} \alpha_{2}$ line I have computed the corresponding value for the electronic charge $e$.

\begin{tabular}{llc}
$\mathrm{Al} \mathrm{Ka}_{1} \mathrm{a}_{2}$ & $\Delta \lambda$ & \\
$8 \cdot 3405 \mathrm{~A}$. & $+2 \cdot 3$ per thousand & $4 \cdot 807$ \\
3406 & $+2 \cdot 3$ & 807 \\
3399 & $+2 \cdot 2$ & 806 \\
3410 & $+2 \cdot 4$ & 808 \\
3373 & $+1 \cdot 9$ & 802 \\
3406 & $+2 \cdot 3$ & 807 \\
3393 & $+2 \cdot 1$ & 805 \\
3397 & $+2 \cdot 2$ & 806 \\
3423 & $+2 \cdot 5$ & 811 \\
\hline $8 \cdot 3401$ & $+2 \cdot 25$ & $4 \cdot 806$
\end{tabular}

As these measurements are based on a direct comparison of X-ray wave-lengths with optical lines of known wave-lengths, the values ought to be free from systematic errors. The accuracy can be estimated from the different values given in the table. The final result is :

$$
\begin{aligned}
\text { Al } K \alpha_{1} \alpha_{2} & =8 \cdot 340 \pm 0.001 \mathrm{~A} . \\
1,000 \mathrm{X} . \mathrm{U} . & =(1.00225 \pm 0.0001) \times 10^{-8} \mathrm{~cm} . \\
e & =(4.806 \pm 0.003) \times 10^{-10} \text { E.S.U. }
\end{aligned}
$$

Further details as to the method and the apparatus will be published elsewhere.

\section{Martin SöDERMaN.}

\author{
Physics Laboratory, \\ Uppsala. \\ Nov. 25.
}

${ }^{1}$ See also Siegbahn and Söderman, Nature, 129, 21, Jan. 2, 1932. 2 Larsson, Diss. Uppsala, Univ. Arsskr., 1929.

\section{Significance of Proknocks in Hydrocarbon Combustion}

OWING to the complicated nature of hydrocarbon molecules with several carbon atoms, it is difficult to obtain precise evidence as to the nature of the chain mechanisms controlling combustion. Further results have been obtained which throw some light on these processes $^{1}$.

A large number of substances have a mild proknock effect as can be measured in knock rating tests ; a special class of substances, however, have a pronounced effect in concentrations as low as $10^{-5}$ and $10^{-6} \mathrm{~mol}$ fraction. These organic compounds are so constituted that they can disrupt to give radicals as follows :-

$$
\mathrm{C}_{2} \mathrm{H}_{8} \mathrm{O} \mathrm{OC}_{2} \mathrm{H}_{5} ; \mathrm{C}_{2} \mathrm{H}_{5} \mathrm{O} \mathrm{OH} ; \mathrm{AcO} \mathrm{OH},
$$

whereas other peroxides, the fissure of which can not take place in this way, show no marked knocking effects ; for example:-<smiles>Cc1coo1</smiles><smiles>CC1(C)OOC1=O</smiles>

Similarly the knocking characteristics of various nitrogen compounds fit in with this, for organic nitrates and nitrites show this same fissure ; Steacie $^{2}$ has shown that ethyl nitrite decomposes thus, $\mathrm{C}_{2} \mathrm{H}_{5} \mathrm{O}$ NO. These compounds have a pronounced proknock effect of the same order as alkyl peroxides. Nitro compounds on the other hand, such as nitromethane and nitrobenzene, possess only a slight proknock effect, because fissure does not occur in this manner.

These remarks also bear relation to the observations of Hinshelwood, Williams and Wolfenden ${ }^{3}$ who show that chain branching in the combustion of hydrogen is due to a similar type of fissure to that discussed above, namely, HO

Amongst many apparently conflicting phenomena associated with combustion, it would seem that this disruption of an already oxygenated molecule may be common to many explosion processes which depend on chain branching. The "centres of high energy from which reaction can spread quicker", to which mention was made in some former investigations ${ }^{4}$, become the regions where disruption occurs. It is interesting to find that the concentrations required for the proknock effect is smaller than $10^{-5}$, since concentrations of antiknock of about the same order are required to prevent it.

The significance of these and other facts relating to the effect of various substances on knocking and on ignition will be discussed elsewhere.

\section{A. R. UBBelohde. \\ A. Egerton.}

\section{Clarendon Laboratory,} Oxford.

1 cf. Egerton and Ubbelohde, NATURE, 133, 179, Feb. 3, 1934 2 Proc. Roy Soc., A., 146, 388; 1934 : and J. Chem. Phys., 2, 345 1934.

${ }^{3}$ Proc. Roy. Soc., A., 147, 48; 1934

- See supplement to NATURE, July 7, 1928.

\section{The Thermal Decomposition of Acetaldehyde}

NaTURE of October 13 and October 27 contain criticisms by Prof. M. W. Travers of work from this laboratory on the thermal decomposition of acetaldehyde. I had already expressed disagreement with similar criticisms at a meeting of the Royal Society in May, and did not wish to enter into a controversy in the columns of NATURE. Lest, however, absence of any comment be interpreted as acceptance, may I be allowed to state quite briefly that fresh experimental work by Dr. Winkler (in process of publication elsewhere) fully confirms that the reaction under the conditions of our previous work is almost entirely homogeneous, and shows by direct chemical analysis that the pressure increase gives a reliable measure of the actual rate of disappearance of acetaldehyde ?

\section{N. Hinshellwood.}

Physical Chemistry Laboratory,

Balliol College and Trinity College, Oxford.

Dec. 15 . 